\title{
High-resolution Anorectal Manometry for Acquired Megarectum in a Patient With Parkinson's Disease
}

\author{
Tae Hee Lee and Joon Seong Lee*
}

Institute for Digestive Research, Soonchunhyang University College of Medicine, Seoul, Korea

A 74-year-old woman previously diagnosed with Parkinson's disease visited the hospital complaining of progressively worsening difficulty with defecation. She had a long history of constipation. A digital rectal examination revealed a hard mass of stool

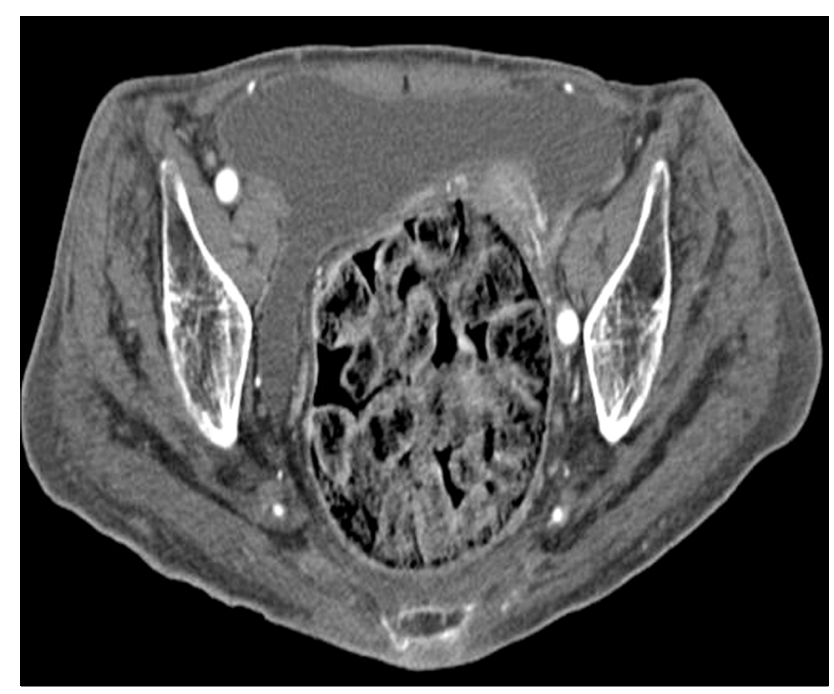

Figure 1. Abdominopelvic CT revealed fecal impaction in a megarectum. in the rectum. Abdominopelvic CT revealed a large amount of fecal material in a megarectum (Fig. 1). High-resolution anorectal manometry (HR-ARM; ManoScan, Sierra Scientific Instruments, Los Angeles, CA, USA) with balloon expulsion was performed.

The HR-ARM showed a low mean resting anal pressure, the maximum squeezing pressure, and incomplete anal relaxation with inadequate propulsive force during defecation suggesting type IV pelvic floor dyssynergia (Fig. 2). ${ }^{1}$ During the rectal bal-

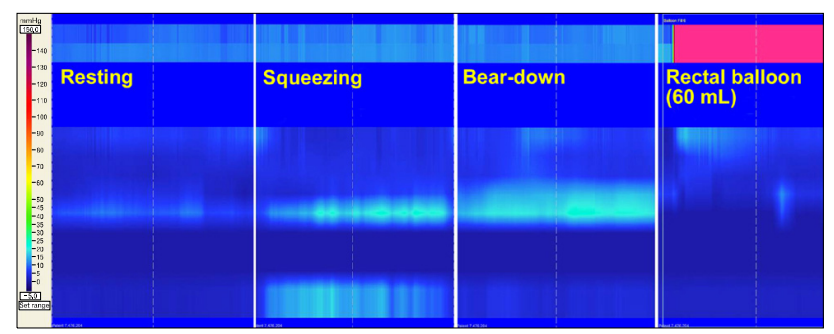

Figure 2. The average resting anal pressure $(4.7 \mathrm{mmHg})$ and maximum squeezing pressure $(17.8 \mathrm{mmHg})$ were low. During defecation, high-resolution anorectal manometry showed incomplete relaxation of the anal sphincter with inadequate propulsive force. During rectal balloon distension, the rectoanal inhibitory reflex was present.

Received: December 22, 2011 Revised: January 6, 2012 Accepted: January 15, 2012

(c) This is an Open Access article distributed under the terms of the Creative Commons Attribution Non-Commercial License (http://creativecommons. org/licenses/by-nc/3.0) which permits unrestricted non-commercial use, distribution, and reproduction in any medium, provided the original work is properly cited.

*Correspondence: Joon Seong Lee, MD Institute for Digestive Research, Soonchunhyang University College of Medicine, 22 Daesagwan-gil, Yongsan-gu, Seoul 140-743, Korea

Tel: +82-2-709-9691, Fax: +82-2-709-9202, E-mail: drjslee@dreamwiz.com

Financial support: None.

Conflicts of interest: None. 
loon dilatation, the rectoanal inhibitory reflex (RAIR) was present, suggesting an intact myenteric reflex, which is absent in Hirschsprung's disease. ${ }^{2}$ The minimum volume for the RAIR was $60 \mathrm{~mL}$.

Preston et $\mathrm{al}^{3}$ defined megarectum in adults as a bowel width $\geq 6.5 \mathrm{~cm}$ at the pelvic brim on a lateral X-ray of the abdomen. Although there is no uniform definition of megarectum for patients with constipation, it is essential to evaluate whether the megarectum is the result or cause of the constipation. Given the presence of RAIR and type IV pelvic floor dyssynergia, HR-ARM provided information that megarectum was not caused by Hirschsprung's disease, but must have resulted from chronic constipation with prolonged fecal impaction.

\section{References}

1. Rao SS, Meduri K. What is necessary to diagnose constipation? Best Pract Res Clin Gastroenterol 2011;25:127-140.

2. Reid JR, Buonomo C, Moreira C, Kozakevich H, Nurko SJ. The barium enema in constipation: comparison with rectal manometry and biopsy to exclude Hirschsprung's disease after the neonatal period. Pediatr Radiol 2000;30:681-684.

3. Preston DM, Lennard-Jones JE, Thomas BM. Towards a radiologic definition of idiopathic megacolon. Gastrointest Radiol 1985;10:167169. 